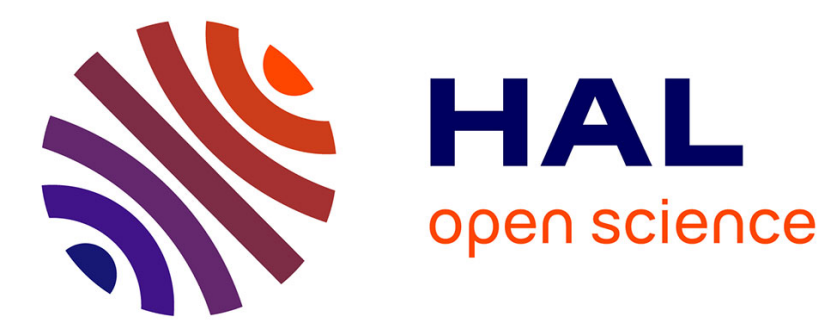

\title{
Superplasticity of a fine-grained TZ3Y material involving dynamic grain growth and dislocation motion
}

G. Bernard-Granger, A. Addad, C. Guizard

\section{To cite this version:}

G. Bernard-Granger, A. Addad, C. Guizard. Superplasticity of a fine-grained TZ3Y material involving dynamic grain growth and dislocation motion. Journal of the American Ceramic Society, 2010, 93 (3), pp.848-856. 10.1111/j.1551-2916.2009.03512.x . hal-00639062

\section{HAL Id: hal-00639062 \\ https://hal.science/hal-00639062}

Submitted on 4 Oct 2021

HAL is a multi-disciplinary open access archive for the deposit and dissemination of scientific research documents, whether they are published or not. The documents may come from teaching and research institutions in France or abroad, or from public or private research centers.
L'archive ouverte pluridisciplinaire HAL, est destinée au dépôt et à la diffusion de documents scientifiques de niveau recherche, publiés ou non, émanant des établissements d'enseignement et de recherche français ou étrangers, des laboratoires publics ou privés.

\section{(c)(1)}

Distributed under a Creative Commons Attribution| 4.0 International License 


\title{
Superplasticity of a Fine-Grained TZ3Y Material Involving Dynamic Grain Growth and Dislocation Motion
}

\author{
Guillaume Bernard-Granger, ${ }^{\dagger, \ddagger}$ Ahmed Addad, ${ }^{\S}$ and Christian Guizard ${ }^{\ddagger}$ \\ ${ }^{\ddagger}$ Laboratoire de Synthèse et Fonctionnalisation des Céramiques, UMR CNRS/Saint-Gobain 3080, Saint-Gobain C.R.E.E., \\ 84306 Cavaillon, Cedex, France
}

${ }^{\S}$ Laboratoire de Structure et Propriétés de l'Etat Solide, UMR CNRS 8008, Université des Sciences et Technologies de Lille, 59655 Villeneuve d'Ascq, Cedex, France

\begin{abstract}
Superplastic deformation of a fully dense TZ3Y material, having a starting grain size around $135-145 \mathrm{~nm}$ and depleted of any amorphous phase at grain boundaries, has been investigated using compressive creep tests in air in the temperature range of $1100^{\circ}-1300^{\circ} \mathrm{C}$ and the real stress range of 50 $100 \mathrm{MPa}$. The key parameters of the creep law have been determined by performing temperature changes at a fixed stress and stress jumps at a fixed temperature. From such experiments, an average value for the apparent stress exponent of around 3 is obtained when the applied stress varied from 50 to $100 \mathrm{MPa}$ and the temperature was kept constant in the range of $1100^{\circ}$ $1300^{\circ} \mathrm{C}$. The apparent activation energy of the mechanism controlling the creep deformation is evaluated at $577 \pm 75 \mathrm{~kJ} / \mathrm{mol}$ in the temperature range of $1200^{\circ}-1300^{\circ} \mathrm{C}$, for a real stress of 70 MPa. The values of the apparent grain size exponent can be calculated from the initial grain size in the as-sintered samples and the grain size in the crept samples. In all cases, it was determined to be around 2. Observation of the microstructure of the crept samples, using scanning electron microscopy, reveals grain growth but does not show any significant elongation of the elemental grains. Transmission electron microscopy of a sample crept under $100 \mathrm{MPa}$ at $1300^{\circ} \mathrm{C}$ reveals clear intragranular dislocation activity. This dislocation activity seems to be mainly confined in folds emitted at triple points. Because the creep parameters (experimental and calculated using a simple geometric model) and the microstructure observed are in good agreement, we propose that the creep mechanism involved is grain boundary sliding accommodated by dynamic grain growth and the formation of triple-point folds.
\end{abstract}

\section{Introduction}

$\mathrm{T}$ HE first observations of a high-temperature superplastic-like behavior for polycrystalline ceramic materials were reported at the end of the seventies and concerned $\mathrm{UO}_{2}$ (in the grain size range of $2-10 \mu \mathrm{m})^{1}$ and $\mathrm{MgO}$ (initial grain size around $0.1 \mu \mathrm{m}$ ), ${ }^{2}$ deformed under compression in air $(\mathrm{MgO})$ or in a specific atmosphere $\left(\mathrm{UO}_{2}\right)$.

Further experiments in the 1980 s by Wakai et al. ${ }^{3}$ revealed superplasticity in fine-grained zirconia. A $3 \mathrm{~mol} \% \mathrm{Y}_{2} \mathrm{O}_{3}$-tetragonal $\mathrm{ZrO}_{2}$ polycrystal (TZ3Y), with a grain size around $0.3 \mu \mathrm{m}$, exhibited an unusual, large strain (over $120 \%$ by nominal strain) when elongated in ambient atmosphere, at a constant displacement rate from $1.1 \times 10^{-4}$ to $5.5 \times 10^{-4} / \mathrm{s}$, for a given temperature of $1450^{\circ} \mathrm{C} .^{3}$

Author to whom correspondence should be addressed. e-mail: guillaume.bernardgranger@saint-gobain.com
Numerous investigations have since been completed on finegrained TZ3Y (grain size always below the micrometer) to identify the mechanism(s) possibly involved in the control of the high-temperature superplastic behavior. ${ }^{4-10}$ Creep (constant load) or constant displacement rate tests were conducted. Interesting reviews, by collecting and interpreting a lot of results originating from different teams around the world, have also been published. ${ }^{11,12}$

The deformation of polycrystalline materials at high temperature is frequently expressed with the following relation: ${ }^{13}$

$$
\dot{\varepsilon}=A \frac{D G b}{k T}\left(\frac{b}{d}\right)^{p}\left(\frac{\sigma}{G}\right)^{n}
$$

where $\dot{\varepsilon}$ is the steady-state strain rate, $A$ is a dimensionless constant, $D$ is the appropriate diffusion coefficient, $G$ is the shear modulus, $b$ is the magnitude of the Burgers vector, $k$ is the Boltzmann's constant, $T$ is the absolute temperature, $d$ is the grain size, $\sigma$ is the imposed stress, and $p$ and $n$ are constants termed the inverse grain size exponent and the stress exponent, respectively. The diffusion coefficient $D$ may be expressed as $D_{0} e^{-Q / R T}$ where $D_{0}$ is a constant preexponential factor, $Q$ is the appropriate activation energy, and $R$ is the gas constant $\left(8.32 \mathrm{~J} \cdot(\mathrm{mol} \cdot \mathrm{K})^{-1}\right)$. Then, relation (1) turns to:

$$
\dot{\varepsilon}=A \frac{D_{0} G b}{k T}\left(\frac{b}{d}\right)^{p}\left(\frac{\sigma}{G}\right)^{n} \mathrm{e}^{-\frac{Q}{R T}}=\Psi\left(\frac{b}{d}\right)^{p}\left(\frac{\sigma}{G}\right)^{n} \frac{\mathrm{e}^{-\frac{Q}{R T}}}{T}
$$

where $\Psi$ is a constant at a given temperature (it is assumed that $G$ does not vary significantly in the temperature range investigated).

Experimental investigations of the deformation of polycrystalline solids at high temperature typically lead to the determination of the $n, p$, and $Q$ parameters. An attempt to identify the possible rate-controlling mechanism, by comparing the values obtained with theoretical predictions, can then be performed. The theoretical models developed for high-temperature deformation are divided into two broad categories: boundary mechanisms, which rely on the presence of grain boundaries and occur only in polycrystalline materials, and lattice mechanisms, which are independent of the presence of grain boundaries and thus occur both in single crystals and polycrystalline materials. ${ }^{13,14}$ Boundary mechanisms are associated with a dependence on the grain size, with the grain-size exponent, $p$, from relation (2) having a value equal to or above 1 . Because lattice mechanisms are confined in the bulk of the elemental grains, in this case, the value of $p$ is 0 . Although most of the theoretical models were originally developed for metallic materials, they can also be applied to ceramics. ${ }^{13}$

Among the different possible mechanisms claimed to control the high-temperature superplastic deformation of ultra-pure (no amorphous phase at grain boundaries) fine-grained TZ3Y, four have been developed to account for the experimental results: ${ }^{15,16}$ 
(i) Two sequential processes: At high stresses, deformation occurs by grain boundary sliding (GBS), which is the slower process; whereas at low stresses, the deformation is controlled by an interface-reaction process. ${ }^{4,8}$

(ii) Interface-controlled diffusional creep: Where the flow process is controlled by a Coble-like mechanism. Such a mechanism requires the existence of grain boundary dislocations, with two requirements: the cores of these dislocations are perfect sources and sinks for vacancies, and the dislocations are evenly spaced in the boundary planes so that they can all climb at the same speed. ${ }^{17}$

(iii) GBS with a threshold stress: With such a threshold stress concept, all the high-temperature deformation parameters of relation (2) can be explained by a single mechanism. The superplasticity is due to GBS accommodated by the recovery slip processes of grain boundary dislocations along the grain boundaries, the climb of dislocations being controlled by the lattice diffusion of cations. ${ }^{11,12}$

(iv) GBS accommodated by intragranular dislocation motion (the recovery of the intragranular dislocations controls the rate of deformation), with a possible threshold stress contribution, at the higher stresses from 15 to $80 \mathrm{MPa}$ and Nabarro-Herring diffusional creep at low stresses. ${ }^{10,38}$

Which of these mechanisms is actually involved is still a matter of intense debate.

In a previous paper, it has been shown that an ultra-pure finegrained TZ3 raw powder can be easily densified with minimal grain growth using spark plasma sintering (SPS) ${ }^{18}$ We investigate in this paper the high-temperature superplastic behavior of such materials, where the relative density is close to $100 \%$ with a minimal grain growth. The results are compared with previous studies.

\section{Experimental Procedure}

A chemically co-precipitated commercially available TZ3Y raw powder (Tosoh Europe B.V., Amsterdam, NL) was selected as the starting material. It was intensively characterized in a previous paper. ${ }^{18}$ This powder is constituted by binder-less spherical spray-dried granules having an average diameter between 10 and $80 \mu \mathrm{m} .{ }^{18}$ Each granule is composed of elemental spherical crystallites having an average diameter between 50 and $70 \mathrm{~nm} .{ }^{18}$

SPS experiments were conducted in vacuum, with the asreceived granulated raw powder (not precompacted at room temperature before the beginning of the tests), on an equipment (SPS-2080, SPS Syntex Inc., Kanagawa, Japan) located at the Plateforme Nationale de Frittage Flash (PNF2, CNRS-CIRIMAT, Université de Toulouse, France). Details for the experimental protocol used can be found in. ${ }^{18}$ Twenty compacts having a final diameter around $8 \mathrm{~mm}$ were prepared using a fixed heating rate of $50^{\circ} \mathrm{C} / \mathrm{min}$, a fixed macroscopic compaction pressure of $100 \mathrm{MPa}$ (applied at $600^{\circ} \mathrm{C}$ and maintained through the entire duration of the test), and the standard 12:2 pulse sequence configuration. The soak temperature was $1125^{\circ} \mathrm{C}$ and the soak duration was fixed to $5 \mathrm{~min}$. All the compacts obtained had a relative density around $95 \%$ (the density of fully dense TZ3Y is assumed to be $6.1 \mathrm{~g} / \mathrm{cm}^{3}$ ) with an average grain size around $80 \mathrm{~nm}$ (see Fig. 6 from reference ${ }^{18}$ ).

To reach full densification, the samples have been submitted to an additional hot isostatic pressing (HIP) step at $1050{ }^{\circ} \mathrm{C}$ for $45 \mathrm{~min}$ with an argon isostatic pressure of $200 \mathrm{MPa}$. Because the as-hipped samples were not stochiometric anymore (black color arising from the reducing conditions of the HIP treatment), they have been annealed at $650^{\circ} \mathrm{C}$ during $60 \mathrm{~min}$. Samples are white again and clearly transparent/translucent. The final density of the samples obtained has been measured using Archimedes method with deionized water (three measurements were made for each sample), proving that all are fully dense.

Parallelepipeds, having the dimensions $5 \mathrm{~mm} \times 2 \mathrm{~mm} \times 2 \mathrm{~mm}$, have been carefully machined in the fully dense samples. Then, compressive creep tests in air have been performed on such parallelepipeds. The real strain of the samples is continuously monitored and the real compaction stress concept (compensation of the load in function of the strain to maintain a constant stress) is applied during each test.

Monotone creep tests have been preformed at $1100^{\circ}, 1200^{\circ}$, $1250^{\circ}$, and $1300^{\circ} \mathrm{C}$ with a fixed compaction stress of $100 \mathrm{MPa}$. To evaluate the contribution of deformation to grain growth (dynamic grain growth), a reference sample, unloaded, is placed at the close vicinity of the creeping sample during each experiment.

In order to minimize the influence of microstructure dispersion on the determination of parameters $n$ and $Q$ from relation (2), these were measured by the stress or temperature change technique, i.e. by modifying the applied stress or the temperature during a test at constant temperature or stress, respectively, and by comparing the strain rates before and after the change. For the determination of the $p$ parameter from relation (2), grain sizes at the end of creep tests and in the as-fully densified material used to machine the creep samples are used, in conjunction with the initial and final strain rates measured during each test at a given temperature.

At this point, it is also critical to specify that, for all the creep tests performed, the samples have been cooled after releasing the applied compression stress.

The microstructure of the as-processed fully dense material and of the reference and crept samples has been investigated by two different techniques. After thermal etching in air $\left(20^{\circ} \mathrm{C}\right.$ below the creep temperature, the heating step and the soak duration represent a total of $70 \mathrm{~min}$ ), scanning electron microscopy (SEM, S4700 FEG, Hitachi High Technologies Europe $\mathrm{GmbH}$, Krefeld, Germany) has been used to investigate the average grain size (image analysis on at least 200 grains) and the morphology of the elemental grains (the surface of the samples is covered with a thin layer of chromium). Thin foils have been also prepared by slicing and careful mechanical polishing (to limit the tetragonal to monoclinic transformation of zirconia) followed by ion milling. For the crept samples, the thin foil section was always perpendicular to the direction of the applied compression stress. The foils have been covered with a thin layer of graphite and observed using a Tecnai G2 20 Twin transmission electron microscope (TEM, FEI Europe, Eindhoven, the Netherlands, acceleration voltage of $200 \mathrm{kV}$, point-to-point resolution of $0.20 \mathrm{~nm}$ ). Additional investigations have also been performed using the high-resolution transmission electron microscopy (HRTEM) mode, especially at the grain boundaries.

\section{Results and Preliminary Comments}

The typical microstructure of the as-processed fully dense material observed using SEM is shown in Fig. 1. No residual porosity is detected. The elemental grains have an equiaxed shape and the average grain size measured is $143 \pm 8 \mathrm{~nm}$.

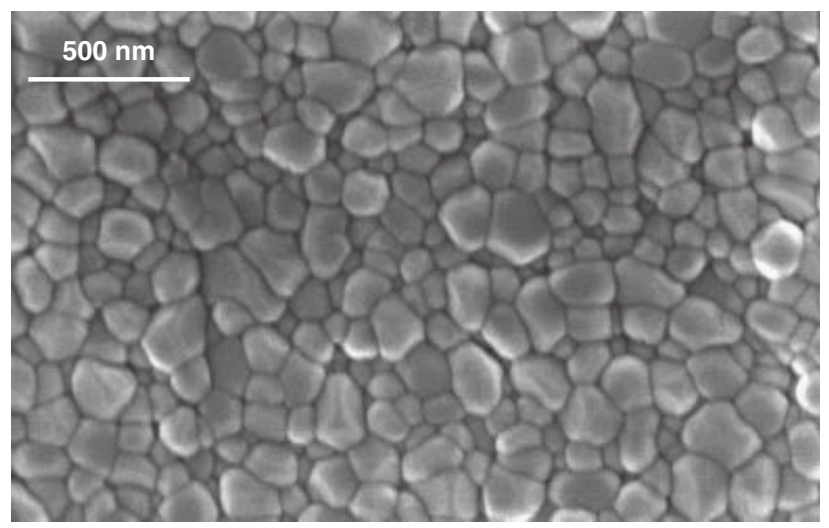

Fig. 1. As-processed (spark plasma sintering+hot-isostatic pressing) microstructure observed by scanning electron microscopy. Annealing treatment has been used to reveal grain boundaries. 


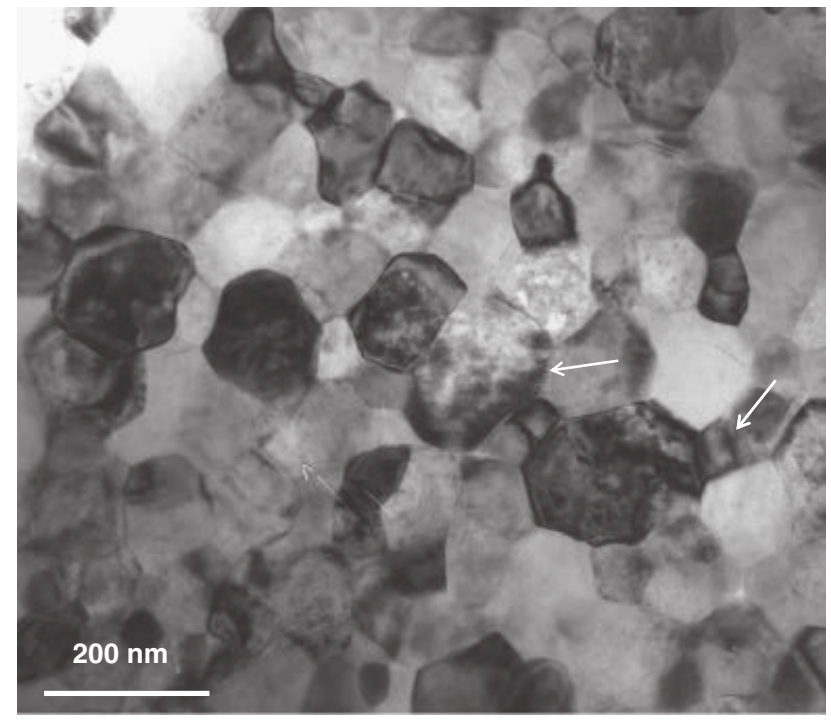

Fig. 2. General aspect of the as-processed (spark plasma sintering+hotisostatic pressing) microstructure observed using transmission electron microscopy. Arrows indicate moiré patterns at grain boundaries.

The typical microstructure of the as-processed fully dense material using TEM is shown in Figs. 2 and 3. Almost all of the elemental grains appear depleted of any dislocation activity (multi two-axis tilting of the thin foil). Some moire patterns are detected (Fig. 2, white arrows), exhibiting the same aspect than those observed after completion of the SPS experiments on the TZ3Y raw powder. ${ }^{19}$ They are specific to the densification mechanism involved during SPS. ${ }^{19}$ HRTEM reveals the lack of an amorphous thin film at the grain boundaries and some rare tiny residual porosities are detected at triple points (Fig. 3).

Results shown in Fig. 4 appear interesting. At $1100^{\circ} \mathrm{C}$, a steady state is reached where a constant creep rate around $1.2 \times 10^{-5} \mathrm{~s}^{-1}$ is obtained. For higher temperatures, no steady state appears and a linear decrease of the logarithm of the creep rate as a function of strain is observed (a small transient stage is observed at $1200^{\circ} \mathrm{C}$ ). According to the work of Wilkinson and Caceres,${ }^{20}$ such a behavior could be a characteristic of dynamic grain growth during the creep experiments. In the intermediate strain rate regime and when static grain growth has a marginal impact on the total growth rate, it has been shown that: ${ }^{20,39-41}$

$$
\dot{d}_{\varepsilon} \approx \dot{d}-\dot{d}_{a} \approx \dot{d} \approx \alpha b_{m} d \dot{\varepsilon}
$$

where $\dot{d}_{\varepsilon}$ is the sliding-induced grain growth rate, $\dot{d}_{a}$ the static annealing grain growth rate, $\dot{d}$ the total grain growth rate, $\alpha$ the

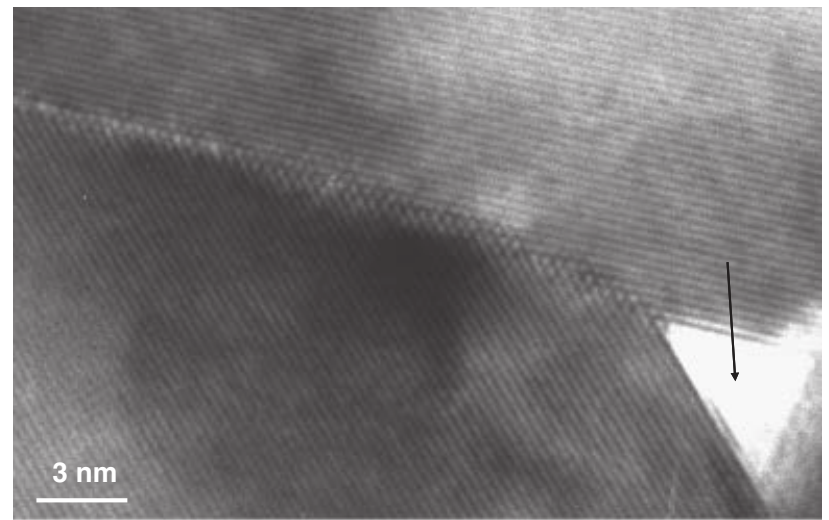

Fig. 3. Details of the as-processed (spark plasma sintering +hot-isostatic pressing) microstructure observed using high-resolution transmission electron microscopy: no amorphous thin film detected at grain boundaries and a residual porosity at triple point (arrow).

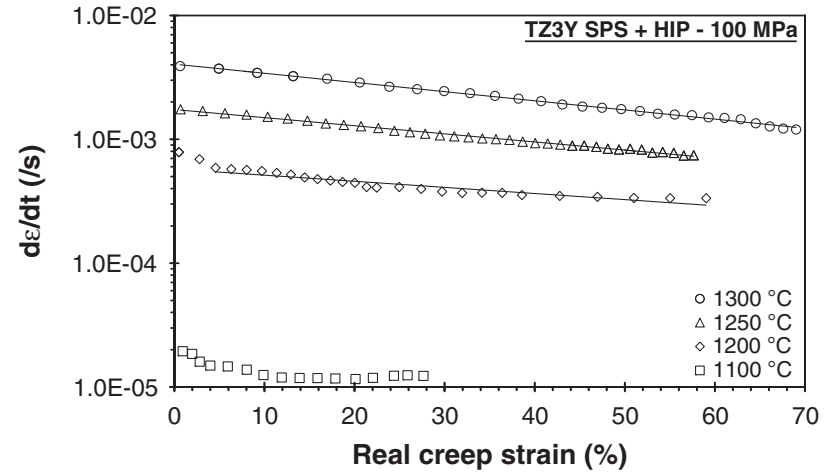

Fig. 4. Creep rate in function of creep strain for different temperatures and a fixed applied compaction stress of $100 \mathrm{MPa}$.

contribution of GBS to the total strain rate $\left(\alpha=\dot{\varepsilon}_{s} / \dot{\varepsilon}, \dot{\varepsilon}_{s} \approx \dot{s} / d\right.$ is the strain rate resulting from GBS with $\dot{s}$ being the GBS rate), and $b_{m}$ the amount of grain boundary migration per unit sliding.

Assuming that $\alpha b_{m}$ is kept constant during the deformation, integrating relation (3) leads to:

$$
d \approx d_{0} e^{\alpha b_{m} \varepsilon}
$$

where $d_{0}$ is the starting grain size of the material that will be crept. In our case, assuming that the grain size will not change significantly during the heating portion of our creep tests, $d_{0}$ is assumed to be the one measured in the as-processed fully dense material $(143 \pm 8 \mathrm{~nm})$.

Using relations (4) and (2), assuming a fixed temperature, a fixed compression creep stress, and only one deformation mechanism characterized by constant values for $n, p$, and $Q$ lead to:

$$
\operatorname{Ln}(\dot{\varepsilon}) \approx K-p \alpha b_{m} \varepsilon
$$

where $K$ is a constant. Then, if grain growth is enhanced by GBS, in which case dynamic grain growth acts as an accommodation process, the variation of the logarithm of the creep rate as a function of the strain should be a straight line with a negative slope. This behavior is typically observed in Fig. 4, for creep experiments on our TZ3Y material, for temperatures in the range of $1200^{\circ}-1300^{\circ} \mathrm{C}$ and a compression stress of $100 \mathrm{MPa}$.

The differences in microstructure for the reference and crept samples that have been exposed at $1100^{\circ}$ or $1300^{\circ} \mathrm{C}$ are shown in Fig. 5. In all cases, whether the samples have been crept or not, the morphology of the grains can be considered as equiaxed, similar to the as-processed fully dense material (Fig. 1). However, the grain size is strongly increased in the sample crept at $1300^{\circ} \mathrm{C}$, in comparison with what is observed in the reference that encountered the same temperature during the same time (Figs. 5(c) and (d)). In the case of the sample crept at $1100^{\circ} \mathrm{C}$, the grain size increase, in comparison with what is observed in the reference sample, is clearly less pronounced than at $1300^{\circ} \mathrm{C}$ (Figs. 5(a) and (b)).

The direct comparison of the grain size measured for the crept and reference samples is shown in Table I. Straightforward calculations show that:

- for a temperature fixed at $1100^{\circ} \mathrm{C}$, the grain size increase in the crept sample is around $9 \%$ with $100 \%$ of this increase being related to dynamic grain growth. Such a total grain growth fraction should be considered as marginal because it is comparable with the uncertainty value related to the method used to evaluate the grain size,

- at $1300^{\circ} \mathrm{C}$, the total fraction of grain growth is $69.2 \%$ in the crept sample, including $52.4 \%$ from dynamic grain growth and $16.8 \%$ from static grain growth

Despite being nonnil, we may consider that static grain growth has a marginal contribution to the total grain growth for all creep temperatures. Inversely, dynamic grain growth is strongly associated with the high-temperature creep deforma- 

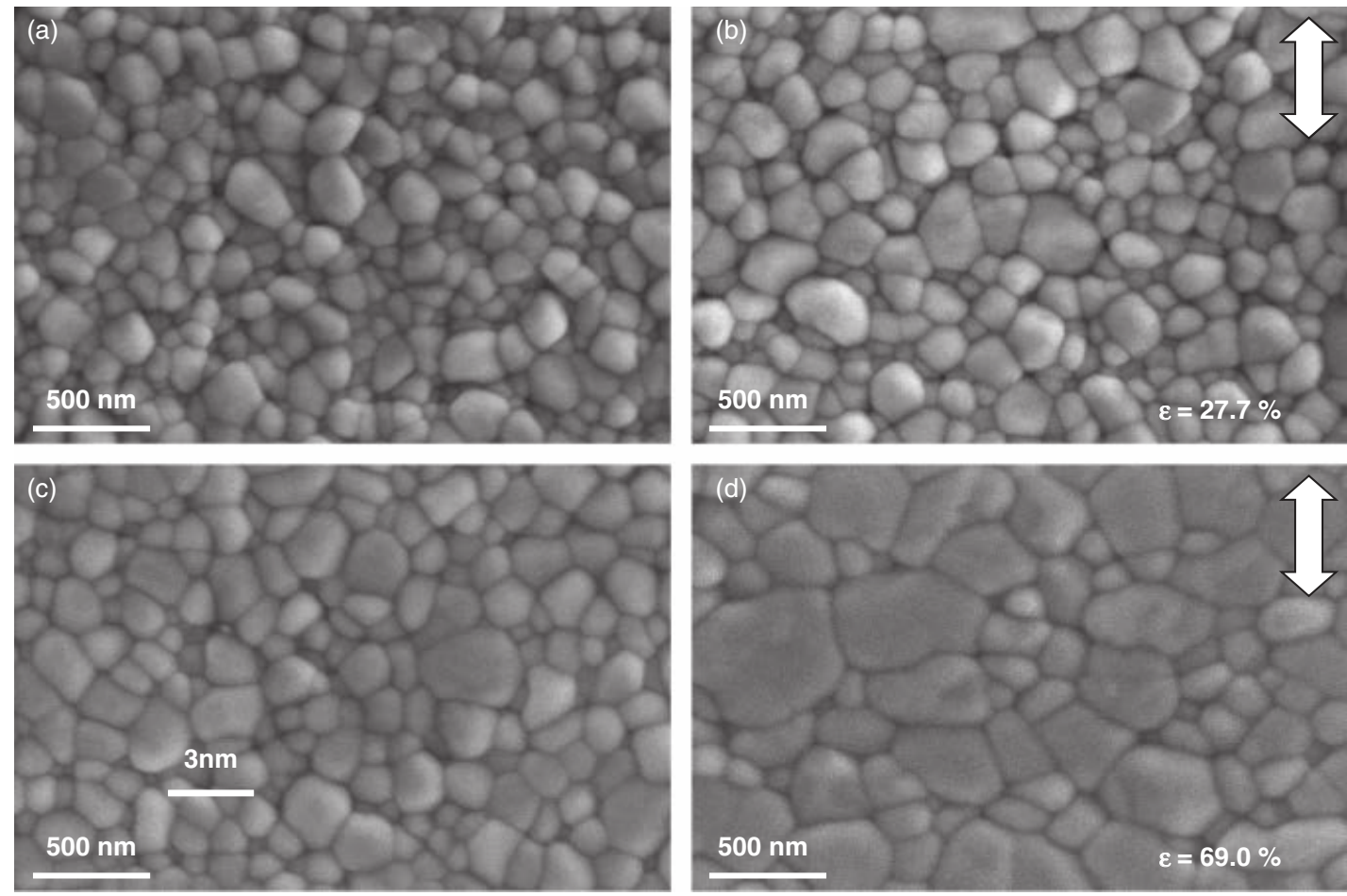

Fig. 5. Microstructure after creep tests in comparison to reference samples exposed during the same time at the same creep temperature but without any applied compaction stress, (a) reference sample $-T=1100^{\circ} \mathrm{C}$, (b) crept $-T=1100^{\circ} \mathrm{C}$, (c) reference sample $-T=1300^{\circ} \mathrm{C},(\mathrm{d}) \mathrm{crept}-T=1300^{\circ} \mathrm{C}$. The white arrow shows the compression axis.

tion of our TZ3Y material, for the experimental conditions retained here, and this parameter cannot be ignored. Then, for temperatures in the range $1200^{\circ}-1300^{\circ} \mathrm{C}$, relation (5) seems appropriate for the description of the strain rate in the function of strain. When the creep temperature is $1100^{\circ} \mathrm{C}$, the questionable very small fraction of dynamic grain growth is not sufficient to affect the shape of the "strain rate versus strain" curve and a stationary stage is reached.

Results obtained for the stress jump experiments, performed for different fixed temperatures in order to determine the value for the $n$ parameter in relation (2) are shown in Table II. The strain rates are summarized, measured just before and after the jumps. They are used to calculate the instantaneous $n$ values (in some cases, a small transient stage is present and extrapolations are used for this calculation). For a compression stress in the range $50-100 \mathrm{MPa}, n$ has a constant value around 3, for creep temperatures in the range $1100^{\circ}-1300^{\circ} \mathrm{C}$.

The results obtained for the temperature jump experiments are shown in Table III. The experiments were performed for a fixed compression stress of $70 \mathrm{MPa}$, in order to determine the value for the $Q$ parameter in relation (2). The strain rates are measured just before and after the jumps, and are used to calculate the instantaneous $Q$ values (as previously, in some cases a small transient stage is present and extrapolations are used for this calculation). For a fixed compression stress of $70 \mathrm{MPa}, Q$ has a value of $577 \pm 75 \mathrm{~kJ} / \mathrm{mol}$ for creep temperatures in the range $1100^{\circ}-1300^{\circ} \mathrm{C}$.

Using the linear interpolations of the logarithm of the creep rate as a function of strain shown in Fig. 4 and knowing the starting and final grain sizes for each creep experiment, it is possible to calculate the value of $p$ in relation (2). The parameters used for these calculations are summarized in Table IV. For a temperature in the range $1200^{\circ}-1300^{\circ} \mathrm{C}, p$ has a constant value around 2 .

The typical aspect of the microstructure observed for the reference sample exposed to a creep temperature of $1300^{\circ} \mathrm{C}$ has been investigated using TEM. Two differences with what is observed in the as-processed fully dense material must be pointed out. Firstly, it seems that the amount of residual pores has increased. Secondly, even if it is a rare event, it appears that some grains contain a moderate dislocation activity. Most of the time, they are one or two long segments running through the grains. Both events may be related to the relaxation of internal stresses, originating from the densification process adopted for the preparation of the fully dense starting TZ3Y material, during the exposition at the creep temperatures.

The typical aspect of the microstructure for the sample crept under $100 \mathrm{MPa}$ at $1300^{\circ} \mathrm{C}$ is shown in Fig. 6. A clear intragranular dislocation activity is seen in a nonnegligible fraction of grains, and in most cases, the dislocation activity is not generalized in all the grain volumes where they do appear. The activity is confined, forming pileups (Fig. 6(a)) running through the grains. Sometimes, the pileups cross over the grain completely (Fig. 6(b)) and they seem to originate from triple points (black arrow). Such typical observations are also reported in the samples deformed at $1200^{\circ}$ and $1250^{\circ} \mathrm{C}$. The sample crept at $1100^{\circ} \mathrm{C}$ has not been investigated so far.

Table I. Evolution of the Grain Size in the Reference and Crept Samples in Function of the Creep Parameters

\begin{tabular}{|c|c|c|c|c|c|}
\hline $\begin{array}{l}\text { Creep } \\
\text { temperature }\left({ }^{\circ} \mathrm{C}\right)\end{array}$ & $\begin{array}{l}\text { Soak duration } \\
\text { (min) }\end{array}$ & $\begin{array}{c}\text { Real } \\
\text { strain (\%) }\end{array}$ & $\begin{array}{l}\text { Initial grain } \\
\text { size }(\mathrm{nm})\end{array}$ & $\begin{array}{l}\text { Final grain size in } \\
\text { the reference sample }(\mathrm{nm})\end{array}$ & $\begin{array}{l}\text { Final grain size in } \\
\text { the crept sample }(\mathrm{nm})\end{array}$ \\
\hline 1100 & 348.0 & 27.7 & $143( \pm 8)$ & $136( \pm 10)$ & $156( \pm 10)$ \\
\hline 1200 & 24.0 & 24.0 & $143( \pm 8)$ & $148( \pm 10)$ & $196( \pm 10)$ \\
\hline 1250 & 8.8 & 57.7 & $143( \pm 8)$ & $158( \pm 10)$ & $209( \pm 10)$ \\
\hline 1300 & 5.4 & 69.0 & $143( \pm 8)$ & $167( \pm 10)$ & $242( \pm 10)$ \\
\hline
\end{tabular}

Real stress $=100 \mathrm{MPa}$. 
Table II. Parameters Used to Calculate the Stress Exponent Coming from Stress Jump Experiments at a Constant Temperature

\begin{tabular}{|c|c|c|c|c|c|}
\hline Stress jump & $50-60 \mathrm{MPa}$ & $60-70 \mathrm{MPa}$ & $70-80 \mathrm{MPa}$ & 80-90 MPa & 90-100 MPa \\
\hline \multirow[t]{2}{*}{$T=1300^{\circ} \mathrm{C}$} & $\operatorname{Ln}\left[S_{50}\right]=-7.315$ & $\operatorname{Ln}\left[S_{60}\right]=-6.908$ & $\operatorname{Ln}\left[S_{70}\right]=-6.515$ & $\operatorname{Ln}\left[S_{80}\right]=-6.215$ & $\operatorname{Ln}\left[S_{90}\right]=-5.915$ \\
\hline & $\begin{array}{c}\operatorname{Ln}\left[S_{60}\right]=-6.815 \\
n \approx 2.7\end{array}$ & $\begin{array}{c}\operatorname{Ln}\left[S_{70}\right]=-6.462 \\
n \approx 2.9\end{array}$ & $\begin{array}{c}\operatorname{Ln}\left[S_{80}\right]=-6.146 \\
n \approx 2.8\end{array}$ & $\begin{array}{c}\operatorname{Ln}\left[S_{90}\right]=-5.908 \\
n \approx 2.6\end{array}$ & $\begin{array}{c}\operatorname{Ln}\left[S_{100}\right]=-5.623 \\
n \approx 2.8\end{array}$ \\
\hline \multirow[t]{2}{*}{$T=1250^{\circ} \mathrm{C}($ decreasing $)$} & $\operatorname{Ln}\left[S_{60}\right]=-8.275$ & $\operatorname{Ln}\left[S_{70}\right]=-7.615$ & $\operatorname{Ln}\left[S_{80}\right]=-7.077$ & $\operatorname{Ln}\left[S_{90}\right]=-6.592$ & $\operatorname{Ln}\left[S_{100}\right]=-6.242$ \\
\hline & $\begin{array}{c}\operatorname{Ln}\left[S_{50}\right]=-8.827 \\
n \approx 3.0\end{array}$ & $\begin{array}{c}\operatorname{Ln}\left[S_{60}\right]=-8.154 \\
n \approx 3.5\end{array}$ & $\begin{array}{c}\operatorname{Ln}\left[S_{70}\right]=-7.535 \\
n \approx 3.4\end{array}$ & $\begin{array}{c}\operatorname{Ln}\left[S_{80}\right]=-6.996 \\
n \approx 3.4\end{array}$ & $\begin{array}{c}\operatorname{Ln}\left[S_{90}\right]=-6.538 \\
n \approx 2.8\end{array}$ \\
\hline \multirow[t]{2}{*}{$T=1200^{\circ} \mathrm{C}($ decreasing $)$} & $\operatorname{Ln}\left[S_{60}\right]=-9.221$ & $\operatorname{Ln}\left[S_{70}\right]=-8.629$ & $\operatorname{Ln}\left[S_{80}\right]=-8.117$ & $\operatorname{Ln}\left[S_{90}\right]=-7.660$ & $\operatorname{Ln}\left[S_{100}\right]=-7.215$ \\
\hline & $\begin{array}{c}\operatorname{Ln}\left[S_{50}\right]=-9.800 \\
n \approx 3.2\end{array}$ & $\begin{array}{c}\operatorname{Ln}\left[S_{60}\right]=-9.140 \\
n \approx 3.3\end{array}$ & $\begin{array}{c}\operatorname{Ln}\left[S_{70}\right]=-8.548 \\
n \approx 3.2\end{array}$ & $\begin{array}{c}\operatorname{Ln}\left[S_{80}\right]=-8.050 \\
n \approx 3.3\end{array}$ & $\begin{array}{c}\operatorname{Ln}\left[S_{90}\right]=-7.538 \\
n \approx 3.1\end{array}$ \\
\hline$T=1100^{\circ} \mathrm{C}$ (decreasing) & - & - & - & $\begin{aligned} \operatorname{Ln}\left[S_{90}\right] & =-11.962 \\
\operatorname{Ln}\left[S_{80}\right] & =-12.308 \\
n & \approx 2.9\end{aligned}$ & $\begin{aligned} \operatorname{Ln}\left[S_{100}\right] & =-11.058 \\
\operatorname{Ln}\left[S_{90}\right] & =-11.385 \\
n & \approx 3.1\end{aligned}$ \\
\hline
\end{tabular}

$n_{1300^{\circ} \mathrm{C}}=2.8 \pm 0.1 / n_{1250^{\circ} \mathrm{C}}=3.2 \pm 0.3 / n_{1200^{\circ} \mathrm{C}}=3.2 \pm 0.1 / n_{1100^{\circ} \mathrm{C}}=3.0 \pm 0.1 S_{x}$ means the creep rate $\left(\mathrm{s}^{-1}\right)$ measured before/after the jump of interest.

\section{Discussion}

\section{(1) Analysis of the Scenarios Exposed in the Introduction Section for the Control of High-Temperature Deformation of TZ3Y}

Scenario (ii) is the most questionable because it does not involve GBS at all. As demonstrated by Lifshitz ${ }^{21}$ and recalled later by Ashby, ${ }^{22}$ during diffusional creep, whether it has a Coble or a Nabarro-Herring characteristic or not, grains of the polycrystal have to change their shape to reflect the overall strain of the deformed sample. Furthermore, if Coble creep is not accommodated by GBS, intergranular cavities will also have to develop when the strain becomes large as in superplasticity. ${ }^{14}$ When the microstructure of ultra-pure fine-grained superplastically deformed TZ3Y samples is observed, it clearly appears that the elemental grains have retained their initial equiaxed shape. . $^{3,8,10,23,24}$ In most cases, a lack of cavity is also observed when samples are deformed in a steady-state regime. ${ }^{8,10,23}$ The tendencies given by observing the microstructure of deformed samples is not in favor of scenario (ii), unless grain growth occurs during the test along with a mechanism of matter redistribution that allows to keep the original equiaxed shape of the grains.

Depending on the experimental conditions, a limited grain growth during the high-temperature deformation tests can be observed $^{3,8,10}$ or not. ${ }^{24}$ The limit of scenario (ii) appears more clearly when looking at recent results, obtained on TZ3Y (grain size around $1 \mu \mathrm{m}$ ), by Duclos. ${ }^{25}$ Using atomic force microscopy performed on crept samples (compression in air, $100 \mathrm{MPa}$, $1260^{\circ} \& 1300^{\circ} \mathrm{C}$, real strain around $15 \%$ ), he determined that around $80 \%$ of the total strain of the sample is imputable to GBS. $^{25}$ Scenario (ii) actually forgets a key conclusion pointed out by Raj: ${ }^{22}$ diffusional flow and sliding are not independent. ${ }^{26}$ They are coupled, and the resulting deformation is correctly described either as diffusional (creep) deformation accommodated by GBS or as GBS with diffusional accommodation. ${ }^{26}$

The description of scenario (i) is unclear. Owen suggests that there are two regions for the creep deformation of a submicron ultra-pure TZ3Y material: ${ }^{8}$ one at low stresses where $n \approx 3$ and $p \approx 1$ (parameters from relation (2)) and another one at high stresses where $n \approx 2$ and $p \approx 3$. The apparent activation energy reported in both regions is around $550 \mathrm{~kJ} / \mathrm{mol}^{8}$ In this frame, the rate-controlling deformation mechanism is thought to be the operation of two sequential processes. It is claimed that at high stresses, deformation occurs by GBS, which is the slower process and therefore controls plasticity, whereas at the lower stresses, the deformation arises from an interface-reaction controlled process for GBS. ${ }^{8}$ This sentence emanating (slightly rewritten by ourselves) from the original article of Owen, is not clear. We understood that in the high stress regime deformation occurs by GBS, accommodated by a mechanism not stated by Owen, and that in the low stress regime deformation occurs by GBS accommodated by the same unknown mechanism that is controlled by an interface-reaction step (sources/sinks of matter/ vacancies are then assumed not perfect ?).

Because GBS is thought to be involved in both stress regimes, it is necessary for an accommodation process to accompany it. If not, extensive cavitation, especially in the vicinity of triple junctions, would occur. Some of the most claimed accommodation possibilities for GBS are grain-boundary migration (dynamic grain growth) ${ }^{20}$ diffusional flow ${ }^{22,26}$ and dislocationslip recovery processes. ${ }^{27-30}$ Sherby ${ }^{30}$ developed a phenomenological model where the $n$ and $p$ parameters in relation (2) are equal to 2 and 3 , respectively, assuming that the dislocation-slip recovery process takes place by grain boundary diffusion for the accommodation of GBS. It has to be underlined that the model from Sherby is, from our knowledge, the only one found in the literature where $n$ is 2 and $p$ is 3. Apparently, this could fit with the $n$ and $p$ experimental values reported by Owen for their submicron ultra-pure TZ3Y material deformed in the high stress regime. The apparent activation energy measured by Owen, around $550 \mathrm{~kJ} / \mathrm{mol}$, should have a grain boundary character. Recent measurements of the grain boundary diffusion coefficient of cations in a submicron ultra-pure TZ3 material gave activation energies of 370 and $390 \mathrm{~kJ} / \mathrm{mol}$ for $\mathrm{Zr}^{4+}$ and $\mathrm{Y}^{3+}$, respectively. ${ }^{31}$ Both values are much lower than the one found by Owen during superplastic deformation of TZ3Y, implying that Sherby's model does not apply for the high stress regime of the results reported by Owen. In the low stress regime, if an interface-reaction exists for the dislocation-slip recovery accommodation for GBS, the apparent activation energy measured should be different than the one measured in the high stress regime. This is not the case. For these reasons, we estimate that scenario (i) remains confusing.

Scenario (iii) is appealing. All the experimental results collected by Jimenez-Melendo on ultra-pure fine-grained TZ3Y fits very well the phenomenological model developed by Sherby, where $n=2$ and $p=2$ in relation (2), ${ }^{30}$ if a threshold

Table III. Parameters Used to Calculate the Activation Energy Coming from Temperature Jump Experiments at a Constant Compaction Stress

\begin{tabular}{lccccc}
\hline Temperature jump & $1100^{\circ}-1200^{\circ} \mathrm{C}$ & $1200^{\circ}-1250^{\circ} \mathrm{C}$ & $1250^{\circ}-1300^{\circ} \mathrm{C}$ & $1300^{\circ}-1250^{\circ} \mathrm{C}$ & $1250^{\circ}-1200^{\circ} \mathrm{C}$ \\
\hline$\sigma=70 \mathrm{MPa}$ & $\operatorname{Ln}\left[T S_{1100}\right]=-5.396$ & $\operatorname{Ln}\left[T S_{1200}\right]=-1.856$ & $\operatorname{Ln}\left[T S_{1250}\right]=-0.523$ & $\operatorname{Ln}\left[T S_{1300}\right]=0.550$ & $\operatorname{Ln}\left[T S_{1250}\right]=-1.233$ \\
& $\operatorname{Ln}\left[T S_{1200}\right]=-1.633$ & $\operatorname{Ln}\left[T S_{1250}\right]=-0.315$ & $\operatorname{Ln}\left[T S_{1300}\right]=0.654$ & $\operatorname{Ln}\left[T S_{1250}\right]=-0.990$ & $\operatorname{Ln}\left[T S_{1200}\right]=-2.721$ \\
& $Q \approx 635 \mathrm{~kJ} / \mathrm{mol}$ & $Q \approx 571 \mathrm{~kJ} / \mathrm{mol}$ & $Q \approx 466 \mathrm{~kJ} / \mathrm{mol}$ & $Q \approx 679 \mathrm{~kJ} / \mathrm{mol}$ & $Q \approx 533 \mathrm{~kJ} / \mathrm{mol}$ \\
\hline
\end{tabular}


Table IV. Parameters Used to Calculate the Grain Size Exponent Using Initial (As-Sintered) and Final (End of Creep) Conditions

\begin{tabular}{lccccc}
\hline Temperature $\left({ }^{\circ} \mathrm{C}\right)$ & $d_{0}(\mathrm{~nm})$ & $\operatorname{Ln}\left[S_{0}\right]$ & $d_{f}(\mathrm{~nm})$ & $\operatorname{Ln}\left[S_{f}\right]$ & $p$ \\
\hline 1300 & 143 & -5.509 & 242 & -6.682 & 2.2 \\
1250 & 143 & -6.354 & 209 & -7.225 & 2.3 \\
1200 & 143 & -7.461 & 196 & -8.089 & 2.0 \\
\hline
\end{tabular}

$p=2.2 \pm 0.1 . \mathrm{S}_{0}$ and $S_{f}$ mean the creep rates $\left(\mathrm{s}^{-1}\right)$ measured at the beginning and at the end of the creep test.

stress is incorporated in relation (2). Then Jimenez-Melendo found an apparent activation energy of $460 \mathrm{~kJ} / \mathrm{mol}$ in the high stress regime. ${ }^{11,12}$ This value is not too far from $500 \mathrm{~kJ} / \mathrm{mol}$, the activation energies reported for the volume diffusion of $\mathrm{Y}^{3+}$ and $\mathrm{Zr}^{4+}$ in ultra-pure fine-grained TZ3Y. ${ }^{31}$ Such trends imply that deformation may occur by GBS accommodated by a dislocation-slip recovery process of grain boundary dislocations in the vicinity of grain boundaries, the recovery process by dislocation climbing being controlled by volume diffusion of the $\mathrm{Y}^{3+}$ and/or $\mathrm{Zr}^{4+}$ cations. ${ }^{11,12}$ If the applied stress approaches the threshold, Jimenez-Melendo argues that GBS becomes difficult and eventually cannot proceed at all if the applied stress falls below the threshold one. ${ }^{11,12}$ Then they proposed that the threshold stress may result from yttrium segregation at grain boundaries and its interaction with the grain boundary dislocations involved in the accommodation process for GBS. ${ }^{11,12}$ The expression proposed for the threshold stress, $\sigma_{0}$, was ${ }^{11,12}$ :

$$
\sigma_{0}(\mathrm{MPa})=5 \times 10^{-4} \frac{\mathrm{e}^{\frac{120 \mathrm{~kJ} / \mathrm{mol}}{R T}}}{d(\mu \mathrm{m})}
$$

The as-processed fully dense TZ3Y material we investigated exhibits a grain size of $143 \pm 8 \mathrm{~nm}$. If relation (6) is valid, it implies that a threshold stress as high as $120-130 \mathrm{MPa}$ should exist when we are completing creep experiments at $1100^{\circ} \mathrm{C}$. Then, if a compression stress of $100 \mathrm{MPa}$ is applied at this temperature, the sample investigated should not creep. However, it is clearly not the case when looking at Fig. 4. When applying a compression stress of $100 \mathrm{MPa}$, the material we investigated reaches a final real strain around $28 \%$, the final grain size being around $156 \mathrm{~nm}$. Furthermore, recent results from Lorenzo-Martin et $a l .{ }^{32}$ show that, when the grain size of a starting almost fully dense ultra-pure TZ1.7Y material (the yttrium segregation at grain boundaries is still present, as for TZ3Y) is around 50-60 $\mathrm{nm}$, superplastic deformation is still possible for applied com- pressive stresses and temperatures in the ranges 5-65 MPa and $1150^{\circ}-1200^{\circ} \mathrm{C}$, respectively. For such a fine grain size, the threshold stress predicted by relation (6) should be around 230 and $160 \mathrm{MPa}$ at $1150^{\circ}$ and $1200^{\circ} \mathrm{C}$, respectively. Such high values are unrealistic and not supported by experimental results obtained byLorenzo-Martin et al. $^{32}$

A second weak point of scenario (iii) should also be mentioned. GBS is claimed to be accommodated by a dislocationslip recovery process of grain boundary dislocations in the vicinity of grain boundaries, the recovery process by dislocation climbing being controlled by volume diffusion of the $\mathrm{Y}^{3+}$ and/or $\mathrm{Zr}^{4+}$ cations. ${ }^{11,12} \mathrm{Up}$ to now and to our knowledge, such grain boundary dislocations have never been observed using TEM investigations. ${ }^{11,12,15,24}$

More recently, Gomez-Garcia et al. ${ }^{42,43}$ has proposed new models to explain the threshold stress approach, in which grain boundary dislocations are not necessary. The main idea of both models is that yttrium segregates at grain boundaries. As a consequence of segregation, grains behave as structures with charged interfaces, separated by a small charge compensating layer. Despite being of a great interest, the models fail to predict the $\mathrm{n}$ and $\mathrm{p}$ experimental values obtained during our investigations. Furthermore, a clear intragranular dislocation activity, that cannot be ignored, is also observed in the present paper. Both new models from Gomez-Garcia do not take into account such an important feature.

Results obtained by Morita, ${ }^{10}$ to built scenario (iv), are indeed very similar to the ones exposed just above in the present paper. For an almost fully dense ultra pure fine grained $(0.35$ $\mu \mathrm{m})$ TZ3Y material, deformed by tensile creep tests in air with an initial stress range of $0.8-80 \mathrm{MPa}$ and a temperature in the range $1300^{\circ}-1400^{\circ} \mathrm{C}$, Morita reported: ${ }^{10}$

- a significant grain growth that cannot be ignored,

- in the high stresses range region, the values of the $n, p$, and $Q$ parameters from relation (2) are 3,2 to 3 and around $570 \mathrm{~kJ} / \mathrm{mol}$, respectively,

- in the same stress range, intragranular dislocation motion is noticeably activated.

Then, they claimed that, for the stress range 50-100 MPa, intragranular dislocation motion contributes to the accommodation of GBS and the recovery of the intragranular dislocations, thanks to a climbing process within the bulk of the elemental grains, controls the rate of deformation. ${ }^{10}$ This interpretation has been challenged by Balasubramanian ${ }^{16}$ and Dominguez-Rodriguez. ${ }^{15}$ Basing their analysis on the expression of the critical tensile stress required to nucleate a dislocation, Balasubramanian argued that this value is roughly $130 \mathrm{MPa}$ at $1400^{\circ} \mathrm{C},{ }^{16}$ therefore much greater than the lowest stress of 15
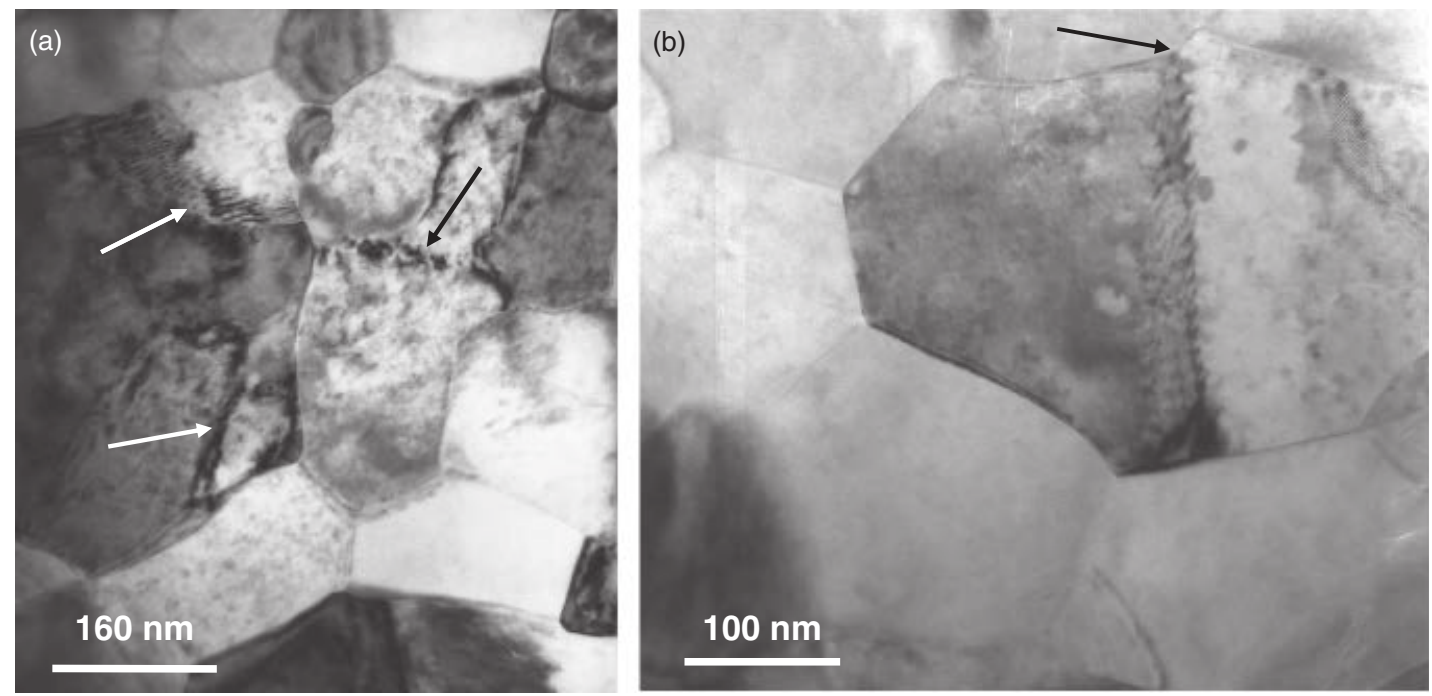

Fig. 6. Typical aspect of the microstructure observed using transmission electron microscopy for the sample crept at $1300^{\circ} \mathrm{C}$ with an applied compaction stress of $100 \mathrm{MPa}$, (a) note intragranular dislocation (arrows), (b) intragranular dislocation fold originating from a triple point (black arrow). 
MPa that has been applied by Morita and where dislocation activity has been reported. ${ }^{10}$ Then, Balasubramanian and Dominguez-Rodriguez focused their argumentation on the pileup structure reported by Morita, such pileups being a potential proof for stress concentration at multiple-grain junctions increasing locally the applied stress. Using simple calculations to investigate the shear stress at the head of grain boundary dislocation pileups along planar boundaries, they concluded that the stress concentration factor is too high to be induced at multiplegrain junctions during GBS. ${ }^{15,16}$ They concluded that the pileups structures observed by Morita must be formed during the cooling step following creep, the cooling step being completed under load. ${ }^{15}$ In a pertinent reply, ${ }^{33}$ Morita underlined that the analysis of Balasubramanian is erroneous because a grain boundary dislocation pileup structure has been considered. Such a structure does not fit with the intragranular dislocation pileups configuration they reported. ${ }^{10}$

At that point, considering the experimental results reported in the present paper, it appears that scenario (iv) emanating from Morita ${ }^{10}$ could be the relevant one controlling the high-temperature creep deformation of the fully dense ultra-pure fined grained TZ3Y material we investigated. However, there is a slight difference between the dislocation configuration we reported and the one reported by Morita. Morita reported a dislocation activity that appears "generalized" in the grains volume. ${ }^{10}$ In our case, it seems that the dislocation activity is more confined in "folds" (in the planar section of the TEM thin foils, a fold exhibits a narrow band morphology containing dislocation pileups) running through the grains (Figs. 6(a) and (b)). These folds seem to originate from triple points (Fig. 6(b)). In the following section, it will be explained that such a particular microstructure could be the consequence of one of the mechanisms that accommodate GBS during the high-temperature creep deformation of the TZ3Y material we investigated.

\section{(2) Prospect for the Mechanism Involved During the High- Temperature Creep Tests Reported}

For the experimental parameters used, Table I showed us that dynamic grain growth is an important phenomenon associated to the high-temperature creep deformation of the TZ3Y material we investigated. Assuming that the deformation enhancement of grain growth is due to damage created at triple junctions by GBS, Wilkinson has perfectly shown (by the use of a geometrical model) how the recovery of this damage by boundary migration enhances the normal grain growth process, ${ }^{20}$ meaning that dynamic grain growth is an accommodation process for GBS.

Let us now recall the climbing rate for an edge dislocation, assuming that climbing proceeds by jog propagation along the dislocation line by absorbing/emitting vacancies. If $V_{c}$ is the climbing rate of the dislocation and $V_{j}$ is the propagation rate for the jog, the climbing rate of the dislocation is simply given by:

$$
V_{c}=C_{j} V_{j}
$$

where $C_{j}$ is the jog concentration on the dislocation line. Straightforward calculations resumed by Poirier ${ }^{34}$ enable to calculate the expression of the climbing rate:

$$
V_{c}=\frac{D_{v} \sigma b^{3}}{k T\left(l_{d}+X\right)}
$$

where $D_{v}$ is the volume diffusion coefficient, $\sigma$ the applied stress, $b$ the magnitude of the Burgers vector, $k$ the Boltzmann's constant, $T$ the absolute temperature, $X$ the average distance betweens jogs on the dislocation line and $l_{d}=\frac{b}{2 \pi} \operatorname{Ln}\left(\frac{R}{b}\right)$ a structural parameter. The expression of $l_{d}$ is directly coming from solving the diffusion problem for a dislocation, positioned at the center of a cylinder having a radius $R$, and admitting that the vacancy concentration far away from the dislocation line is the same as the one for thermal equilibrium $\left(C_{0}\right)$. $^{34}$
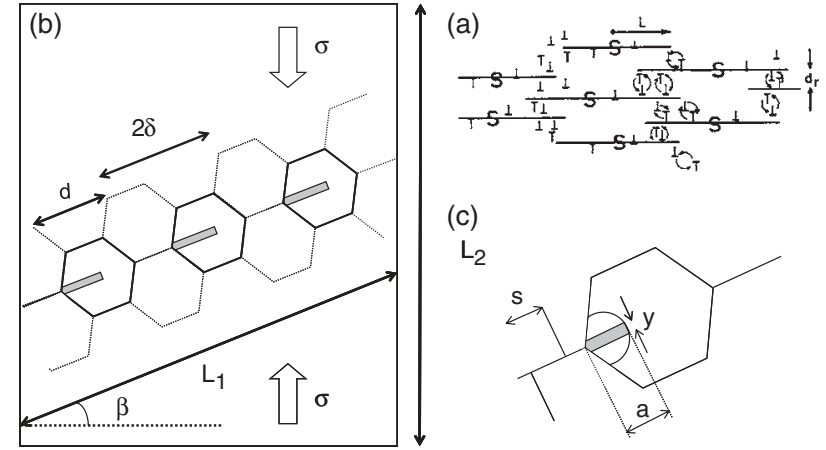

(c)

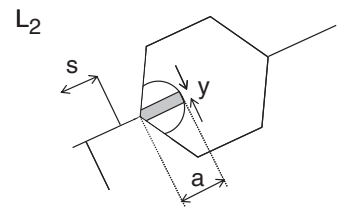

Fig. 7. (a) Dislocation configuration used in Weertman's model,${ }^{35}$ (b) (derived from Gifkins ${ }^{37}$ ): (b) model used for calculation of creep rate dependent upon dislocation glide and climb, (c) details for progressing accommodation of grain boundary sliding within a grain by triple-point fold formation.

The dislocation model proposed by Weertman has been frequently cited for the climb-controlled creep mechanism in metals and alloys ${ }^{35}$ and has been simply resumed by Poirier. ${ }^{34}$ It is based on a typical hardening (dislocation multiplication)/recovery (dislocation climbing) equilibrium, the recovery step controlling the creep strain. As shown in Fig. 7(a), it is assumed that dislocation loops are emitted from sources $(S)$, situated in neighboring reticular plans separated by a distance $d_{r}$. It is also assumed that $L$ is the radius of the heading loops and that the average loop radius is $L / 2$. The creep rate expression is given by:

$$
\dot{\varepsilon}_{w}=\rho_{m} b \frac{\Lambda}{\Delta} V_{c}
$$

where $\rho_{m}$ is the density of mobile dislocations, $\Lambda$ and $\Delta$ are the sliding and climbing distance, respectively. The dislocations of Fig. 7(a), that form a dipole, climb towards each other, anneal and enable emission of a new loop. Then, the average sliding distance is $L / 2$ for a climbing distance of $d_{r} / 2$.

Straightforward calculations resumed by Poirier ${ }^{34}$ (assuming some hypothesis proposed by Hazzledine for the maximum number of dipoles which can be formed between two sources ${ }^{36}$ ), using expression (8) for the climbing rate, lead to the following expression for the final creep rate:

$$
\dot{\varepsilon}_{w} \propto \frac{1}{\gamma b} \frac{G b^{3}}{k T} \frac{D_{v}}{l_{d}+X}\left(\frac{\sigma}{G}\right)^{3}
$$

where $G$ is the shear modulus and $\gamma$ has a typical value around $6 .^{36}$

We can now use the model shown in Fig. 7(b) that has been slightly modified with respect to the original one developed by Gifkins. ${ }^{37}$ It is now assumed that the dislocation activity, based on the formalism developed by Weertman and exposed just above, is confined in triple-point folds (gray lamellas in Fig. 7(b)) that extend into the elemental grains forming a polycrystal. Such a behavior is seen as a consequence of stress concentration at triple edges, imputable to GBS, which is assumed to be the deformation mechanism. Then, it signifies that the formation of triple-point folds will be seen as an accommodation process for GBS. Implicitly from the model developed by Gifkins, the grain boundaries are supposed to be inert for the dislocations motion. It signifies that dislocations are free to go from one grain to another one without any limitation and that they are able to reach the sample surface at the end of their travel. In a certain sense, it seams that grain boundaries and triple points, where the generation of folds proceeds, are only seen as a periodic array, dispersed in a monocrystal, enabling dislocation emission.

If a sliding distance $s$ causes a dislocation, having a Burgers vector $b$, to move a distance $u^{*}$ in the fold, there will be an effec- 
tive offset $m^{*}$ at the specimen surface due to the dislocation movement. Then:

$$
m^{*}=\frac{u^{*} b}{L_{1}}
$$

With a mobile dislocation density per fold $\rho^{*}$, the offset per fold may be approximated to (the surface of a fold is assumed to be a rectangle):

$$
m^{*} \rho_{m}^{*} a y
$$

where $y$ is the fold width and $a$ its extension in the grains, as shown on Fig. 7(c).

Using simple geometric considerations from Fig. 7(b), summing for all dislocations in a row of unit elements of width $2 \delta$ and for all dislocations stacked in a direction perpendicular to the direction of propagation of the folds (stacking periodic distance is $\lambda$ ), the total shear strain, $\Gamma$, is then simply given by

$$
\Gamma=\frac{4 u^{*} b \rho_{m}^{*} a y}{3 \sqrt{3} d^{2}}
$$

Derivation of relation (13) and conversion of shear rate to compressive strain rate yields:

$$
\dot{\varepsilon}=\frac{4 \chi b \rho_{m}^{*} a y}{3 \sqrt{3} d^{2}} \frac{d u^{*}}{d t}
$$

where $\chi$ is a suitable constant to convert from shear to compression strain rate.

Having in mind what has been exposed above considering the model developed by Weertman and considering that the fold problematic is a confinement of the Weertman's configuration, $\frac{d u^{*}}{d t}=\bar{V}^{*}$ is then the average dislocation velocity, which takes into account the fact that each dislocation has to glide and climb in the folds. Then:

$$
\dot{\varepsilon}=\frac{4 \chi b \rho_{m}^{*} a y}{3 \sqrt{3} d^{2}} \bar{V}^{*}
$$

Because the formation of the folds is resulting from the applied stress concentrated by sliding at triple edges, a stress concentration factor, $F$, has to be involved for the confinement configuration of Weertman's problem. Then, as proposed by Gifkins, ${ }^{37}$ we are assuming that:

$$
\rho_{m}^{*} \bar{V}^{*}=F \rho_{m} \bar{V}
$$

where $\bar{V}$ is the average dislocation velocity in the problem analyzed by Weertman and $\rho_{m}$ has been introduced previously in relation (9).

Because in Weertman's configuration the dislocations have to glide a distance $\Lambda=\mathrm{L} / 2$ and to climb a distance $\Delta=d_{r} / 2$, the average dislocation velocity is given by (the shear strain is roughly the one related to gliding, the time of the glide-climb event is roughly the climbing one):

$$
\bar{V}=\frac{\Lambda}{\Delta} V_{c}=\frac{L}{d_{r}} V_{c}
$$

Then, using relations (17) and (16), expression (15) becomes:

$$
\dot{\varepsilon}=\frac{4 \chi b F \rho_{m} a y}{3 \sqrt{3} d^{2}} \frac{L}{d_{r}} V_{c}
$$

Using relation (9), the creep strain because of GBS accommodated by triple-point folds, with the folds formation being climb-controlled, is finally given by:

$$
\dot{\varepsilon}=\frac{4 \chi \text { Fay }}{3 \sqrt{3} d^{2}} \dot{\varepsilon}_{w}
$$

Combining relation (10) and (19) and stating that $D_{v}=D_{v}^{0} e^{-Q_{v} / R T}\left(D_{v}^{0}\right.$ is a constant frequency factor and $Q_{v}$ is the activation energy for the lattice diffusion of the involved species) gives:

$$
\dot{\varepsilon} \propto \frac{4 \alpha D_{v}^{0}}{3 \sqrt{3} \gamma} \frac{G}{k T}\left(\frac{b}{d}\right)^{2}\left(\frac{\sigma}{G}\right)^{3} \frac{\mathrm{e}^{-\frac{Q_{v}}{R T}}}{l_{d}+X} \text { Fay }
$$

If the jog concentration on the dislocation line is high and favors an easy process for emission/absorption of vacancies, then $X \ll l_{d}$. Because $l_{d}$ is also proportional to $b$, the creep rate becomes:

$$
\dot{\varepsilon} \propto \frac{4 \alpha D_{v}^{0}}{3 \sqrt{3} \gamma} \frac{G b}{k T}\left(\frac{\sigma}{G}\right)^{3} e^{-\frac{Q_{v}}{R T}} \frac{\text { Fay }}{d^{2}}
$$

If the dislocations are sources/sinks of vacancies having a low efficiency, then $l_{d}$ is negligible in comparison to $X$. It is possible to show that $C_{j}=\frac{b}{X} \cdot{ }^{34}$ If the jogs are in thermal equilibrium, we can write $C_{j}=C_{j}^{0} e^{-\frac{Q_{j}}{R T}}$ where $C_{j}^{0}$ is the reference jog concentration and $Q_{j}$ is the activation energy for the formation of jogs. Then, the creep rate expression becomes:

$$
\dot{\varepsilon} \propto \frac{4 \alpha D_{v}^{0} C_{j}^{0}}{3 \sqrt{3} \gamma} \frac{G b}{k T}\left(\frac{\sigma}{G}\right)^{3} e^{-\left(\frac{Q_{v}+Q_{j}}{R T}\right)} \frac{\text { Fay }}{d^{2}}
$$

It is critical to note that both relations (21) and (22) predict values for the $n$ and $p$ parameters from relation (2) that have been experimentally reported on the ultra-pure fine-grained TZ3Y material we investigated (Section III). We can now focus on the measured apparent activation energy $(577 \pm 75 \mathrm{~kJ} / \mathrm{mol})$. This value is moderately higher than $460-500 \mathrm{~kJ} / \mathrm{mol}$, the activation energy reported for the volume diffusion of $\mathrm{Y}^{3+}$ and $\mathrm{Zr}^{4+}$ in ultra-pure fine-grained TZ3Y materials. ${ }^{11,12,31}$ Therefore we cannot exclude a possible contribution from a jog formation step to the apparent activation energy experimentally measured. Another point has to be clarified. The validity of relations (21) and (22) implies that the morphology of the folds (a and y parameters) is independent on the grain size. When looking at Fig. 6(b), it seams that the fold extension could be close to the grain size. In fact, the first TEM investigations show that such a particular configuration shown on Fig. 6(b) is not a generality. Most of the time, the fold extension is limited inside the grain where they develop. However, complementary observations are needed to definitively validate this hypothesis.

Finally, let us discuss a little bit around the threshold stress concept that is widely admitted for fine-grained TZ3Y materials deformed at high temperatures. Jimenez-Melendo has analyzed deformation data obtained on TZ3Y polycrystals, with grain size below the micrometer and deformed in the temperature range $1250^{\circ}-1450^{\circ} \mathrm{C}$, as a function of stress, grain size and impurity content. ${ }^{11,12}$ For the purer materials (impurity content below $0.1 \mathrm{wt} \%$, same situation encountered for the material we investigated in the present paper) there was a transition in stress exponent from $n=2$ (region II) to $n \geq 3$ (region I) when the stress was decreased. ${ }^{11,12}$ This kind of experimental results can be correlated well with a single deformation process that incorporates at threshold stress $\sigma_{0}$ below which GBS cannot proceed. ${ }^{11,12}$ In that case the strain rate is proportional to $\left(\sigma-\sigma_{0}\right)^{2}$, then $n=2$ whatever the stress investigated. The new model proposed in the present paper does not take into account the possibility of a threshold stress contribution to the deformation of the TZ3Y material we investigated. Indeed, the clear intragranular dislocation activity observed by TEM in our crept samples supports the model exposed, where $\mathrm{n}$ is really 3 and not hedged because the applied stress approaches a threshold one during the experiments. In the future, it would be interesting to complete additional investigations on our material, especially using lower creep stresses. Then, by combining creep test results and careful TEM investigations, we will be able to conclude on the threshold 
stress concept that could possibly applies also to our material at much lower stresses than the ones investigated here.

Because the experimental results are in agreement with what is predicted using a simple theoretical model, we propose a deformation mechanism for the ultra-pure fine-grained TZ3Y material investigated here. In the temperature and stress ranges retained, we suggest that superplastic deformation occurs by GBS accommodated by two mechanisms: dynamic grain growth and triple-point folds. The fold formation is based on a hardening (dislocation multiplication)/recovery (dislocation climbing) equilibrium, where recovery is the limiting step. Climbing is also supposed to be controlled by volume diffusion of the $\mathrm{Y}^{3+}$ and/or $\mathrm{Zr}^{4+}$ cations, with a possible contribution of jogs formation on the dislocation lines.

\section{Conclusion}

The superplastic behavior of a fully dense ultra-pure finegrained (around $145 \mathrm{~nm}$ ) TZ3Y material has been investigated by compressive creep tests in air. The temperature range was $1100^{\circ}-1300^{\circ} \mathrm{C}$ and the applied stress varied between 50 and 100 $\mathrm{MPa}$.

Analyzing the crept microstructures using TEM, two main changes have been reported in comparison to the microstructure observed in the as-processed fully dense material. For all creep conditions, dynamic grain growth and an intragranular dislocation activity are observed. The dislocation activity is not generalized to the complete volume of the grains but seems to be confined in folds.

Using a simple theoretical model, adapted from a previous work reported by Gifkins, ${ }^{38}$ we propose what the deformation mechanism of the TZ3Y material investigated could be. This model gives theoretical values of the creep parameters (stress exponent, grain size exponent and apparent activation energy) in good agreement with the experimental ones. In the temperature and stress ranges investigated, it is suggested that superplastic deformation occurs by GBS accommodated by two mechanisms: dynamic grain growth and triple-point folds. The fold formation is possibly based on a hardening (dislocation multiplication)/recovery (dislocation climbing) equilibrium, where recovery is the limiting step. Climbing is also thought to be controlled by volume diffusion of the $\mathrm{Y}^{3+}$ and/or $\mathrm{Zr}^{4+}$ cations, with a possible contribution of jogs formation on the dislocation lines.

\section{References}

${ }^{1}$ T. E. Chung and J. Davies, "The Low-Stress Creep of Fine Grain Uranium Oxide," Acta Metall., 27 [4] 627-35 (1979).

${ }^{2}$ J. Crampon and B. Escaig, "Mechanical Properties of Fine-Grained Magnesium Oxide at Large Compressive Strains," J. Am. Ceram. Soc., 63 [11-12] 680-6 (1980).

${ }^{3}$ F. Wakai, S. Sakagushi, and Y. Matsuno, "Superplasticity of Yttria-Stabilized Tetragonal $\mathrm{ZrO}_{2}$ Polycrystals," Adv. Ceram. Mater., 1 [3] 259-63 (1986).

${ }^{4}$ M. M. R. Boutz, A. J. A. Winnubst, A. J. Burgraaf, M. Nauer, and C. Carry, "Low Temperature Superplastic Flow of Yttria Stabilized Tetragonal Zirconia Polycrystals," J. Eur. Ceram. Soc., 13 [2] 103-11 (1994).

${ }^{5}$ A. Lakki, R. Schaller, M. Nauer, and C. Carry, "High Temperature Superplastic Creep and Internal Friction of Yttria Doped Zirconia Polycrystals," Acta Metall. Mater., 41 [10] 2845-53 (1993).

${ }^{6}$ B. Amana, R. Duclos, and J. Crampon, "Stress Influence on the Deformation Mechanisms of Tetragonal Zirconia Polycrystals," Ceram. Int., 18 [6] 385-90 (1992).

${ }^{7}$ Y. Ma and T. G. Langdon, "A Critical Assessment of Flow and Cavity Formation in a Superplastic Yttria-Stabilized Zirconia," Acta Metall. Mater., 42 [8] 2753-61 (1994).

${ }^{8}$ D. M. Owen and A. H. Chokshi, "The High Temperature Mechanical Characteristics of Superplastic 3 mol\% Yttria Stabilized Zirconia,” Acta Mater., 46 [2] 667-79 (1998).

${ }^{9}$ I. Charit and A. H. Chokshi, "Experimental Evidence for Diffusion Creep in the Superplastic $3 \mathrm{~mol} \%$ Yttria-Stabilized Tetragonal Zirconia," Acta Mater., 49 [12] 2239-49 (2001).

${ }^{10} \mathrm{~K}$. Morita and K. Hiraga, "Critical Assessment of High-Temperature Deformation and Deformed Microstructure in High-Purity Tetragonal Zirconia Containing 3 mol.\% Yttria," Acta Mater., 50 [5] 1075-85 (2002).

${ }^{11}$ M. Jimenez-Melendo, A. Dominguez-Rodriguez, and A. Bravo-Leon, "Superplastic Flow of Fine-Grained Yttria-Stabilized Zirconia Polycrystals: Consti- tutive Equation and Deformation Mechanisms," J. Am. Ceram. Soc., 81 [11] 276176 (1998).

${ }^{12} \mathrm{M}$. Jimenez-Melendo and A. Dominguez-Rodriguez, "High Temperature Mechanical Characteristics of Superplastic Yttria-Stabilized Zirconia. An Examination of the Flow Process," Acta Mater., 48 [12] 3201-10 (2000).

${ }^{13}$ A. H. Chokshi and T. G. Langdon, "Characteristics of Creep Deformation in Ceramics," Mater. Sci. Technol., 7, 577-84 (1991).

${ }^{14}$ T. G. Langdon, "Deformation of Ceramic Materials"; pp. 101-26 in Grain Boundary Deformation Processes, Edited by R. C. Bradt, and R. E. Tressler. Plenum Press, New-York, 1975.

${ }^{15}$ A. Dominguez-Rodriguez, D. Gomez-Garcia, and M. Castillo-Rodriguez, "A Critical Assessment of the Dislocation-Driven Model for Superplasticity in Yttria Tetragonal Zirconia Polycrystals," J. Eur. Ceram. Soc., 28 [3] 571-5 (2008).

${ }^{16} \mathrm{~N}$. Balasubramanian and T. G. Langdon, "Flow Processes in supeRplastic Yttria-Stabilized Zirconia: A Deformation Limit Diagram," Mater. Sci. Eng. A 409 [1-2] 46-51 (2005)

${ }^{17}$ M. Z. Berbon and T. G. Langdon, "An examination of the Flow Process in Superplastic Yttria-Stabilized Tetragonal Zirconia," Acta Mater., 47 [8] 2485-95 (1999).

${ }^{18}$ G. Bernard-Granger and C. Guizard, "Spark Plasma Sintering of a Commercially Available Granulated Zirconia Powder-I. Sintering Path and Hypotheses About the Mechanism(s) Controlling Densification," Acta Mater., 55 [10] 3493504 (2007)

${ }^{19}$ G. Bernard-Granger, C. Guizard, S. Surblé, G. Baldinozzi, and A. Addad, "Spark Plasma Sintering of a Commercially Available Granulated Zirconia Powder-II. Microstructure After Sintering and Ionic Conductivity," Acta Mater., 56 [17] 4658-72 (2008).

${ }^{20} \mathrm{D}$. S. Wilkinson and C. H. Caceres, "On the Mechanism of Strain-Enhanced Grain Growth During Superplastic Deformation," Acta Metall., 32 [9] 1335-45 (1984)

${ }^{21}$ I. M. Lifshitz, "On the Theory of Diffusion-Viscous Flow of Polycrystalline Bodies," Soviet Phys. JETP, 17 [4] 909-20 (1963).

${ }^{22}$ M. F. Ashby and R. A. Verrall, "Diffusion-Accommodated Flow and Superplasticity," Acta Metall., 21 [2] 149-63 (1973).

${ }^{23}$ S. Primdahl, A. Thölen, and T. G. Langdon, "Microstructural Examination of a Superplastic Yttria-Stabilized Zirconia: Implications for the Superplasticity Mechanism," Acta Metall. Mater., 43 [3] 1211-8 (1995).

${ }^{24}$ A. Dominguez-Rodriguez, A. Bravo-Leon, J. D. Ye, and M. Jimenez-Melendo, "Grain Size and Temperature Dependence of the Threshold Stress for Superplastic Deformation in Yttria-Stabilized Zirconia Polycrystals," Mater. Sci. Eng. A, 247 [1-2] 97-101 (1998).

${ }^{25}$ R. Duclos, J. Crampon, and C. Carry, "Grain-Boundary Sliding and Accommodation Mechanism During Creep of Yttria-Partially-Stabilized Zirconia," Phil. Mag. Lett., 82 [10] 529-33 (2002).

${ }^{26}$ R. Raj and M. F. Ashby, "On Grain Boundary Sliding and Diffusional Creep," Met. Trans., 2 [4] 1113-27 (1971).

${ }^{27}$ T. G. Langdon, "Grain Boundary Sliding as a Deformation Mechanism During Creep," Phil. Mag., 22 [178] 689-700 (1970).

${ }^{28}$ A. K. Mukherjee, "The Rate Controlling Mechanism in Superplasticity," Mater. Sci. Eng., 8 [2] 83-9 (1971).

${ }^{29}$ R. C. Gifkins, "Grain-Boundary Sliding and its Accommodation During Creep and Superplasticity," Metall. Trans., 7A [8] 1225-32 (1976).

${ }^{30}$ O. D. Sherby and J. Wadsworth, "Deformation, Processing and Structure"; pp. 355-89 in Development and Characterization of Fine Grain Superplastic Material, Edited by G. Krauss. ASM, Metal Park, OH, 1984.

${ }^{31}$ S. Swaroop, M. Kilo, C. Argirusis, G. Borchardt, and A. H. Chokshi, "Lattice and Grain Boundary Diffusion of Cations in 3YTZ Analyzed Using SIMS," Acta Mater., 53 [19] 4975-85 (2005).

${ }^{32}$ C. Lorenzo-Martin, D. Gomez-Garcia, A. Gallardo-Lopez, A. DominguezRodriguez, and R. Chaim, "An Explanation of the High Temperature Creep of Yttria Tetragonal Zirconia Nanocrystals," Scr. Mater., 50 [8] 1151-5 (2004).

${ }^{33} \mathrm{~K}$. Morita and K. Hiraga, "Reply to "Comment on the Role of Intragranular Dislocations in Superplastic Yttria-Stabilized Zirconia”,"' Scr. Mater., 48 [9] 14037 (2003).

${ }^{34}$ J. P. Poirier, Plasticité à haute température des solides cristallins, pp. 119-25. Editions Eyrolles, Paris, France, 1976.

${ }^{35}$ J. Weertman, "Dislocation Climb Theory and Steady-State Creep," Trans. ASM, 61, 681-94 (1968).

${ }^{36}$ P. M. Hazzledine, "Work Hardening in Easy Glide," Can. J. Phys., 45, 765-75 (1967).

${ }^{37}$ R. C. Gifkins, "The Grain-Size Dependence of Creep Rate in Recovery Creep," J. Aust. Inst. Metals, 18 [3] 137-45 (1973).

${ }^{38}$ K. Morita and K. Hiraga, "Deformed Structures in Fine-Grained Tetragonal Zirconia," Phil. Mag. Let., 81 [5] 311-9 (2001).

${ }^{39}$ D. S. Wilkinson, "Superplasticity"; pp. 6.1-6.6 in Grain Size Effects in Superplasticity, Edited by B. Baudelet, and M. Suery. Éditions du Centre National de la Recherche Scientifique, Paris, 1985.

${ }^{40}$ I. W. Chen and L. A. Xue, "Development of Superplastic Structural Ceramics," J. Am. Ceram. Soc., 73 [9] 2585-609 (1990).

${ }^{41}$ F. Béclin, R. Duclos, J. Crampon, and F. Valin, "Microstructural Superplastic Deformation in MgO. $\mathrm{Al}_{2} \mathrm{O}_{3}$ Spinel," Acta Metall. Mater., 43 [7] 2753-60 (1995).

${ }^{42}$ D. Gomez-Garcia, C. Lorenzo-Martin, A. Munoz-Bernabé, and A. Dominguez-Rodriguez, "Correlation Between Yttrium Segregation at the Grain Boundaries and the Threshold Stress for Plasticity in Yttria-Stabilized Tetragonal Zirconia Polycrystals," Phil. Mag., 83 [1] 93-108 (2003).

${ }^{43}$ D. Gomez-Garcia, C. Lorenzo-Martin, A. Munoz-Bernabé, and A. Dominguez-Rodriguez, "Model of High-Temperature Plastic Deformation of Nanocrystalline Materials: Application to Yttria Tetragonal Zirconia," Phys. Rev. B, 67, $144101(2003)$ 